\title{
Awareness and attitudes regarding electroconvulsive therapy (ECT) among patients and caregivers at a psychiatry unit in a tertiary care hospital in Sri Lanka
}

T Gunasekera, R Fernando, MUPK Peris, KALA Kuruppuarachchi, A Hapangama

\begin{abstract}
Introduction

Electroconvulsive therapy (ECT) is a life-saving procedure in certain psychiatric conditions and is also extremely effective for treatment resistant psychiatric conditions. Despite the proven safety and efficacy there appears to be unease and stigma attached to ECT. Exploration about the awareness and attitudes regarding ECT among patients and caregivers can improve the practice of ECT.
\end{abstract}

\section{Aims}

The aim of this study was to describe awareness and attitudes about ECT among patients and their caregivers.

\section{Methods}

This was a descriptive cross-sectional study carried out among patients and caregivers attending psychiatric facilities at a tertiary care hospital in Sri Lanka, using an interviewer administered questionnaire.

\section{Results}

Out of 221 participants, 54\% were caregivers. Among the participants, $65 \%$ thought that ECT is a treatment used for psychiatric disorders. There was no signifi- cant association between educational level and awareness about ECT ( $p>0.05)$. The most common source of knowledge about ECT was doctors (43\%), but $69 \%$ felt doctors have not explained about ECT prior to treatment. Cognitive issues (46\%) were the most commonly feared side effect; $5 \%$ thought ECT does not have a scientific basis and $20 \%$ felt it is an inhuman mode of treatment. Of those interviewed, $38 \%$ were of the opinion that they would receive ECT if recommended.

\section{Conclusions}

Doctors were the most important source of information regarding ECT and a significant proportion of the participants knew that it is used in treating psychiatric disorders. Only a minority thought ECT didn't have a scientific basis and a considerable proportion were willing to undergo ECT if recommended. Despite popular beliefs this cohort of participants appeared to have a favourable awareness about ECT.

Key words: electroconvulsive therapy, awareness, attitudes, stigma

SL J Psychiatry 2020; 11(2): 20-25

\section{Introduction}

Electroconvulsive therapy (ECT) is the application of an electrical current under general anesthesia to a specific area of the brain to elicit a generalized seizure (1). With high rates of mortality associated with mental illnesses, ECT is regarded as a life-saving procedure in some psychiatric disorders and is also extremely effective in conditions where adequate trials of other treatment modalities such as psychotropic and or psychological treatment have proven ineffective or poorly effective (2-4).
Despite evidence for the safety and efficacy there appears to be an unease and stigma regarding the use of ECT in treating mental illnesses, which appears to undermine the acceptance of this treatment by the general public (5-7). This may be due to historical and at times improper and unregulated use of ECT, as well as due to the paucity of knowledge regarding ECT itself, leading to various misconceptions and negative attitudes among patients, their caregivers and the general public (8). On most occasions, controversy regarding ECT seems to be 
driven by the aspects related to its administration and the associated side effects (mainly the associated memory loss) (9).

Reasonable knowledge about ECT among the patients has been shown as a desirable attribute in the therapeutic intervention with ECT $(9,10)$. Research in this important area in Sri Lanka is scarce. Therefore, it is important that patients' and their caregivers' awareness and attitudes about ECT is better understood by the treating clinicians. The objective of this study was to describe the awareness and attitudes towards ECT among patients and their caregivers attending psychiatric facilities at a tertiary care hospital in Sri Lanka.

\section{Methods}

This was a descriptive cross sectional study carried out among all patients (excluding patients who are grossly psychotic or acutely manic and participants who are acutely intoxicated) and their caregivers above the age of 18 years, attending in-patient or out-patient psychiatric facilities of the North Colombo Teaching Hospital Sri Lanka. Only those who gave written informed consent were included in the study. Data was gathered during two consecutive months (February and March, 2019) via an interviewer administered questionnaire. The questionnaire gathered information about knowledge, misconceptions, concerns and attitudes towards ECT among the study population. Data was analyzed using the IBM SPSS ${ }^{\circledR}$ software program. Ethical approval to carry out this research was obtained from the Ethics Review Committee of the Faculty of Medicine, University of Kelaniya, prior to commencement of the study.

\section{Results}

\section{Demographic characteristics}

The total sample size was 221 , with $54.3 \%$ of the study population being caregivers and the remainder being patients (either in-patient or out-patient). The mean age of the study group was 42 years, and $59.7 \%$ of the study population had an education above GCE ordinary level (Table 1).

\section{Awareness and knowledge about ECT among the total study population}

Out of the total study population, 65\% of participants (i.e., 32\% of caregivers and 33\% of patients) were aware that ECT is a treatment modality used for psychiatric disorders. However, $24.4 \%$ of the study participants were of the opinion that ECT is a treatment modality for malignancies, while $9 \%$ thought that it is a form of treatment used in rheumatology. Of the study participants, $58 \%$ were of the opinion that ECT was utilized in managing violence in the absence of a mental illness, and $18.6 \%$ were of the view that it is being used to punish people. There was no statistical significance between the educational level and the awareness that ECT is a treatment modality for mental illnesses $(p=0.216)$ (Table 2). Out of those who were aware that ECT is a treatment for mental illnesses, $43.3 \%$ reported medical professionals as the main source of information; for $43.4 \%$ the source of information had been a relative, while in $10.4 \%$ the information had been obtained from social media.

When individual psychiatric disorders were considered, $43 \%$ were aware that ECT was used as an effective treatment modality for depressive illnesses, while the figures for schizophrenia and puerperal psychiatric disorders respectively were $26.7 \%$ and $19 \%$. There was no significant difference regarding this knowledge between caregivers and patients $(\mathrm{p}<0.05)$. In our study group, 24\% were aware that ECT can be administered to women after child birth, while 30\% thought that it should not be administered to pregnant women at any stage of the pregnancy, and also that it should not be given to people above the age of 60 years.

\begin{tabular}{|l|c|c|}
\hline \multicolumn{2}{|c|}{ Table 1. Characteristics of the study population } \\
\hline Characteristics of the study population & $\begin{array}{c}\text { Patients }(n=120) \\
\text { Number (\%) }\end{array}$ & $\begin{array}{c}\text { Caregivers }(n=101) \\
\text { Number (\%) }\end{array}$ \\
\hline Age group & & $1(0.9)$ \\
Less than 20 years & - & $29(28.7)$ \\
$21-40$ years & $37(30.8)$ & $71(70.3)$ \\
Above 40 years & $83(69.2)$ & $80(79.2)$ \\
Level of education & & $23(22.7)$ \\
Up to or completed year 11 & $73(60.8)$ & $47(39.1)$ \\
Above year 11 & & \\
\hline
\end{tabular}


Table 2. Correlations between participant level of education and the awareness and attitudes regarding ECT

\begin{tabular}{|c|c|c|c|c|}
\hline & \multicolumn{3}{|c|}{ Education level } & \multirow{2}{*}{$\begin{array}{l}\text { Level of } \\
\text { significance } \\
(p)\end{array}$} \\
\hline & $\begin{array}{l}\text { Primary } \\
\text { education } \\
(n=18)\end{array}$ & $\begin{array}{l}\text { Secondary } \\
\text { education } \\
(n=133)\end{array}$ & $\begin{array}{l}\text { Tertiary } \\
\text { education } \\
(n=70)\end{array}$ & \\
\hline \multicolumn{5}{|l|}{ Negative attitudes towards ECT } \\
\hline $\begin{array}{l}\text { a. It's an inhuman way } \\
\text { of treatment }(n=43)\end{array}$ & 4 & 30 & 9 & 0.006 \\
\hline $\begin{array}{l}\text { b. Does not have any scientific } \\
\text { evidence }(n=11)\end{array}$ & 2 & 6 & 3 & 0.361 \\
\hline $\begin{array}{l}\text { c. Does not involve any } \\
\text { anesthesia during the } \\
\text { procedure }(n=27)\end{array}$ & 4 & 15 & 8 & 0.972 \\
\hline $\begin{array}{l}\text { d. Used as a punishment } \\
\text { method }(n=41)\end{array}$ & 7 & 19 & 15 & 0.426 \\
\hline
\end{tabular}

Of the participants, 5\% thought that ECT does not have a scientific basis in treating psychiatric illnesses and $19.5 \%$ thought it was an inhuman way of treating patients. And $12 \%$ of the participants were of the view that ECT was administered without general anesthesia. Furthermore, $15.8 \%$ of the participants feared that people who receive ECT at some point had a greater risk in developing a seizure disorder in the future, compared to a person who has not received ECT. There was no statistical difference between caregivers and patients, with regards to these opinions.

\section{Awareness and knowledge about the procedure and side effects of ECT}

Fifty three percent (53\%) out of the total 120 patients who participated in the study had received ECT in the past. However, 39.1\% were not aware why they had been given ECT and 34.4\% were not aware about the procedure. Seventy five percent (79\%) were not aware of any side effects of the treatment. Of the patients or caregivers of patients who had received ECT in the past, $68.8 \%$ were of the opinion that they were not adequately informed about the reason for ECT or the procedure.

Among those who had received ECT in the past, headache (93.8\%), body aches (75\%) and short-term memory problems (68.6\%) were reported as the commonest side effects. Of those who had received ECT, 84.2\% believed that their mental illness would have worsened if ECT was not administered at that point in their illness, and $29.7 \%$ believed that they would have died if they had not received ECT. And $46.9 \%$ of those who had received ECT in the past were of the view that that they would receive ECT again if recommended.

Out of the 157 participants who did not have a past history of either being treated or having a relative being treated with ECT, 57\% were aware that patient was administered a general anesthetic prior to receiving ECT, and 75.7\% were aware that a small electric current was applied during the procedure. However $90.1 \%$ were not aware that the patient may have a seizure during the procedure. In this group where neither the patient nor the caregiver had received ECT in the past, only $10 \%$ were aware of the side effects of ECT; of those who knew about side effects, $83 \%$ reported headache as a possible side effect, while $70 \%$ reported possible short-term memory problems and body aches as common side effects.

\section{Attitudes about ECT}

Negative attitudes such as ECT being used to punish or take revenge $(p=0.002)$ and that ECT is an inhuman way of treatment ( $p=0.004$ ) were significantly more common among those participants whose main source of information regarding ECT was mass media (with no significant difference between patients and caregivers regarding these attitudes). Of all the participants, 45.6\% were of the opinion that they would recommend ECT for any of their relatives or friends. 


\section{Discussion}

\section{Awareness and knowledge about ECT}

In our study sample more than half of the participants were aware of ECT as a treatment modality for psychiatric illnesses. Doctors were the commonest source of knowledge for the patients and their caregivers in this group. In contrast, a study done in Pakistan has reported mass media as the commonest source of knowledge regarding ECT for the patients and their caregivers (10). The fact that our study was conducted among a group of service users, rather than in the community may have influenced this finding.

We did not find a significant association between the participant's awareness that ECT is being used as a treatment modality in psychiatric disorders and the participants' educational attainment, although work in Pakistan has reported that patients with a lower educational level were significantly more likely to have a poorer knowledge regarding ECT as a treatment modality (10). Again, the fact that the participants in our study were service users may have influenced our findings.

About $43 \%$ of our study population was aware that ECT is a treatment modality for depressive illnesses. However, despite proven efficacy and being recommended by worldwide guidelines such as National Institute for Health and Care Excellence (NICE guidelines) for the treatment of antenatal as well as postnatal psychiatric disorders, almost two third of our study population were of the view that ECT should not be used in any stage of pregnancy and half of our study population were of the view that ECT should not be used in postpartum period $(3-5,11)$. This appears to be a common public misconception, and similar findings have been reported from India (9).

A quarter of our study participants were of the opinion that ECT was indicated for malignancies, and a minority thought it was used for rheumatological disorders. These findings suggest that patients and caregivers either misidentify or misperceive ECT as radiotherapy or infrared therapy. This may be due to the use of colloquial language among the general public to describe ECT in mental illnesses, as well as radiotherapy in malignancies and infrared therapy in rheumatological diseases, as "administration of a current", and indicates the need for clearer explanations for patients and caregivers.

The misconception of ECT being used to manage violence in the absence of a mental illness appears to be common not only among this study population of patients and their caregivers but also among medical students, as has been shown in a study conducted previously in the United States of America (12). Cognitive side effects were the most feared among the participants of our study, similar to previous findings from India and Pakistan $(9,10)$.

\section{Source of information, procedure and side effects of ECT}

Medical practitioners were the commonest source of information regarding ECT for our study population, in contrast to studies done in India and Pakistan where the commonest source was the media $(9,19)$. The fact that our participants were either patients or caregivers in touch with medical services may have influenced this finding. However, a significant proportion of the patients in our study group, who had been treated with ECT in the past, were of the opinion that they were not given adequate information regarding the indication for ECT, its procedure or the side effects, by the treating team. Evidence suggests that unsatisfactory explanations about treatment with ECT and deficiencies in the process of obtaining consent is a common concern among the patients and their caregivers across developing countries (20).

\section{Attitudes regarding ECT}

Negative attitudes (inhuman ways of treating patients, being used as a punishment method) towards ECT was significantly more prominent among participants whose source of knowledge regarding ECT was through mass media. Over-dramatization and descriptions of improper and incorrect details about the procedure of ECT through mass media may contribute to the development of misconceptions and a public sense of fear regarding ECT (13). Studies done in Australia and New Zealand also report similar negative attitudes towards ECT among participants whose source of knowledge was through movies $(14,15)$. However, some studies have reported a positive use of media for dissemination of knowledge regarding ECT (16-18).

Some of the participants in this study were of the opinion that their mental illness would have worsened or that they would have died of they had not received ECT, and similar to this, a study done in the United Kingdom also reports patients describing how ECT "gave them their lives back again" (21). Just below half of the patients who had received ECT in the past in our study said they would be happy to receive it again if indicated, and a study done in the United Kingdom has also reported similar findings $(21,22)$.

\section{Limitations}

Study participants in this study were limited to those who were services users of a psychiatry unit. The awareness and attitudes of services users of other disciplines in the hospital and the general public may differ from patients who use psychiatry services. 


\section{Conclusions}

This study examines the role of the medical practitioner as a source of information and also explores participants' knowledge about the scientific basis of ECT, which are some of the least researched areas with regards to the knowledge and perception of ECT (23). The cohort of participants in this study appears to have a reasonably positive awareness and attitudes regarding ECT. Psychiatrists should take a lead role in improving the knowledge of patients and the general public regarding ECT through patient information sessions, newsletters, press releases and other communication modalities. If done effectively, this will not only improve the awareness and attitudes of the patients, care givers and the general public towards ECT, but also reduce the stigma attached to a very effective mode of treatment.

\section{Statement of contribution}

$\mathrm{AH}$ is the principal investigator and developed the research concept, wrote the research proposal, conducted the data analysis and wrote the manuscript. RS was involved in writing the research proposal and collection of data. TG was involved in the data collection, data analysis and writing of the manuscript. MUPKP and KALAK were involved in writing of the manuscript. All authors have seen and approved the final version of the manuscript.

\section{Conflicts of interest}

None declared

T Gunasekera, R Fernando, MUPK Peris, KALA Kuruppuarachchi, A Hapangama, Department of Psychiatry, Faculty of Medicine, University of Kelaniya, Sri Lanka

Corresponding author: A Hapangama

Email: ahapangama@kln.ac.lk

http://orcid.org/0000-0002-5477-5050

\section{References}

1. Petrides G, Tobias KG, Kellner CH, Rudorferc MV. Continuation and Maintenance Electroconvulsive Therapy for Mood Disorders: Review of the Literature. Neuropsychobiology 2011; 64(3): 129-40.

2. Walker ER, McGee RE, Druss BG. Mortality in Mental Disorders and Global Disease Burden Implications. A Systematic Review and Meta-analysis. JAMA Psychiatry. 2015; 72(4): 334-41.
3. Payne NA, Prudic J. Electroconvulsive Therapy Part I: A Perspective on the Evolution and Current Practice of ECT. J Psychiatr Pract 2009; 15(5): 346-68.

4. Song G, Tian X, Shuai T, Yi L,Zeng Z, et al. Treatment of Adults with Treatment-Resistant Depression: Electroconvulsive Therapy Plus Antidepressant of Electroconvulsive Therapy Alone? Evidence from an Indirect Comparison Meta-Analysis. Medicine (Baltimore) 2015; 94(26): 1052.

5. Trevino K, McClintock SM, Husain MM. A Review of Continuation Electroconvulsive Therapy: Application, Safety, and Efficacy. JECT 2010; 26(3): 186-95.

6. Payne NA, Prudic J. Electroconvulsive Therapy Part II: A Biopsychosocial Perspective. J Psychiatr Pract 2009; 15(5): 369-90.

7. Lauber C, Nordt C, Falcato L, et al. Can a seizure help? The public's attitude toward electroconvulsive therapy. Psychiatry Res 2005;134: 205-9.

8. Ottosson JO. Use and misuse of electroconvulsive treatment. Biol Psychiatry 1985; 20(9): 933-46.

9. Chavan BS, Kumar S, Arun P, Bala C, Singh T. ECT: Knowledge and attitude among patients and their relatives. Indian J Psychiatry 2006; 48(1): 34-8.

10. Arshad M, Arham Z, Arif M, Bano M, Bashir A, et al. Awareness and perceptions of electroconvulsive therapy among psychiatric patients: a cross-sectional survey from teaching hospitals in Karachi, Pakistan. BMC Psychiatry 2007; 7: 27

11. National Institute for Health and Care Excellence. Antenatal and postnatal mental health: clinical management and service guidance, 2014. https://www.nice.org.uk/guidance/ cg192 (accessed on Aug 25, 2019).

12. Clothier JL, Freeman T, Snow L. Medical student attitudes and knowledge about ECT. J ECT 2001; 17(2); 99-101.

13. McDonald A, Walter G. The portrayal of ECT in American movies. J ECT. 2001; 17: 264-74.

14. Walter G, McDonald A, Ray J, Rosen A. Medical Student Knowledge and Attitudes Regarding ECT Prior to and After Viewing ECT Scenes from Movies. The J ECT 2002; 18(1): 43-46.

15. Kerr RA, McGrath JJ, O’kearney RT, John P. ECT: Misconceptions and Attitudes. Aust N Z J Psychiatry 1982; 16(1): 43-9.

16. Bird JM, Effects of the media on attitudes to electric convulsion therapy. Br Med J 1979; 2: 526-7.

17. Battersby M, Ben-Tovim D, Eden J. Electroconvulsive Therapy: A Study of Attitudes and Attitude Change after Seeing an Educational Video. Aust N Z J Psychiatry 1993; 27(4): 613-19.

18. Oldewening K, Lange RT, Willan S, Strangway C, Kang $\mathrm{N}$, Iverson GL. Effects of an education training program on attitudes to electroconvulsive therapy. J ECT 2007; 23: 82-8. 
19. Dan A, Grover S, Chakrabarti S. Knowledge and Attitude of Patients with Psychiatric Disorders and their Relatives Toward Electroconvulsive Therapy. Indian J Psychol Med 2014; 36(3): 264-9.

20. Chakrabarti S, Grover S, Rajagopal R. Perceptions and Awareness of Electroconvulsive Therapy Among Patients and Their Families: A Review of the Research From Developing Countries. J ECT 2010; 26. 317-22.

21. Griffiths C, O’Neill-Kerr A, Thompson R. Patient reported experience of electroconvulsive therapy (ECT).
Neuropsychiatry 2018; 8(5):1571-6. 10.4172/Neuropsychiatry.1000493

22. Rayner L, Kershaw K, Hanna D, Chaplin R. The patient perspective of the consent process and side effects of electroconvulsive therapy. J Ment Health 2009; 18(5): 379-88. 10.3109/09638230802523013

23. Tsai J, Huang M, Wilkinson ST, Edelen C, Rosenheck RA, Holtzheimer PE. A Measure to Assess Perceptions and Knowledge About Electroconvulsive Therapy: Development and Psychometric Properties. J ECT 2020; 36(1): e1-e6. 